\title{
Congenital Bicuspid Aortic Valves Associated with Coarctation of the Aorta in Children ${ }^{\star}$
}

\author{
ROY L. TAWES, JR. $\dagger$, COLIN L. BERRY, AND EOIN ABERDEEN \\ From Cardio-thoracic Unit, The Hospital for Sick Children, Great Ormond Street, London W.C.1
}

The association of congenital bicuspid aortic valves with coarctation of the thoracic aorta has long been recognized. The incidence has been estimated to be as high as 85 per cent by Edwards et al. (1965), and as low as 25 per cent by Abbott (1936). This disparity, and the frequency of aortic murmurs in children with coarctation, prompted this review.

\section{SUBJECTS AND METHODS}

The 15-year experience of the cardiac clinic at this hospital from 1953 to 1967 , with 429 children under 14 years of age with coarctation, was reviewed. The aortic valves of 119 available post-mortem specimens were re-examined, and the incidence of bicuspid valves and valvar stenosis determined. This necropsy incidence was then compared with the clinical incidence of aortic valvar disease in children in whom aortic valvar disease has been documented at operation, or by cardiac catheterization and angiocardiography.

\section{RESULTS}

Post-mortem Study. Of the 119 hearts examined, 32 had bicuspid aortic valves, an incidence of 27 per cent. No calcific aortic stenosis or evidence of subacute bacterial endocarditis was noted. Anatomical valvar incompetence could not be accurately assessed in these specimens which had been stored in formalin. Eight hearts had obvious aortic stenosis (an incidence of $7 \%$ ), five of these having tricuspid valves, and one bicuspid. Two had subvalvar stenosis.

The form of the abnormal valves is shown in the

Received July 11, 1968.

* This study was supported by the British Heart Foundation.

† Giannini Foundation Fellow. Department of Surgery, University of California Medical Center, San Francisco, California, U.S.A.
Fig. Valves in which the commissure between the right and left coronary cusps was represented by a band or ridge at the base of the undivided cusp were most frequently seen (16 cases). Bicuspid valves without evidence of subdivision (13 cases) generally had one cusp slightly larger than the other (see Edwards, 1961). This pattern of distribution is in agreement with other reported series (Lindesmith et al., 1967; Thomson and Fisher, 1965; Spencer et al., 1960).

Clinical Study. Of the 250 children who are living, and for whom long-term follow-up data are available, 32 have verified aortic valve disease, predominantly aortic stenosis, an incidence of 13 per cent. It is not known how many of these children have bicuspid aortic valves, or how many others with aortic murmurs have bicuspid valves without significant stenosis or regurgitation.

\section{Discussion}

In this survey of coarctations in a paediatric agegroup, 27 per cent had bicuspid aortic valves at necropsy. This is a considerably lower incidence than the 85 per cent quoted by Edwards et al. (1965) and the $\mathbf{4 2}$ per cent reported by Reifenstein, Levine, and Gross (1947). It is similar to the 25 per cent incidence reported both by Abbott (1936) and by Keith, Rowe, and Vlad (1967). Bacon and Matthews (1959) have suggested that this wide variance has resulted from differences in criteria and approach.

Congenital bicuspid aortic valves are predisposed to the complications of calcific stenosis, regurgitation (incompetence), and bacterial endocarditis (Nadas, 1963; Gasul, Arcilla, and Lev, 1966). Edwards (1961) has indicated that uncomplicated bicuspid valves can develop progressive regurgitation which 


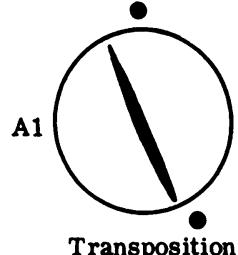

Transposition
A
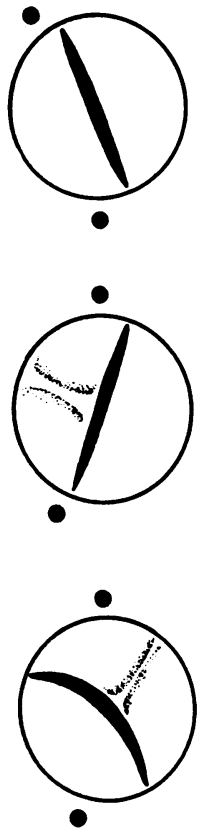

D

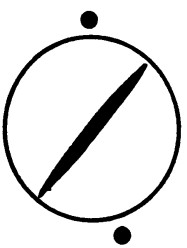

13

16 the hearts. Of 250 living cases, 32 or 13 per cent have aortic stenosis or regurgitation, and are being followed at The Hospital for Sick Children, Great Ormond Street. It is not known how many of these children have bicuspid aortic valves.

\section{REFERENCES}

2 Abbott, M. (1936). Atlas of Congenital Cardiac Disease. American Heart Association, New York.

Bacon, A. P. C., and Matthews, M. B. (1959). Congenital bicuspid aortic valves and the aetiology of isolated aortic valvular stenosis. Quart. F. Med., 28, 545.

Christensen, N. A., and Hines, E. A., Jr. (1948). Clinical features in coarctation of the aorta: a review of 96 cases. Proc. Mayo Clin., 23, 339.

Edwards, J. E. (1961). The congenital bicuspid aortic valve (Editorial). Circulation, 23, 485.

1

FIG.-The variety of valvular appearances seen in this series.

may lead to the complications mentioned above. Of patients with a coarctation and a murmur of aortic regurgitation, 20 per cent are estimated to have bicuspid aortic valves (Christensen and Hines, 1948).

In our experience, aortic murmurs are present in about one-quarter of the children with coarctation. It is very difficult in many cases, without special cardiac investigation, to differentiate which murmurs result from flow across a bicuspid aortic valve that is not stenotic or incompetent. Angiocardio- 